


\section{DISCLAIMER}

This report was prepared as an account of work sponsored by an agency of the United States Government. Neither the United States Government nor any agency thereof, nor any of their employees, makes any warranty, express or implied, or assumes any legal liability or responsibility for the accuracy, completeness, or usefulness of any information, apparatus, product, or process disclosed, or represents that its use would not infringe privately owned rights. Reference herein to any specific commercial product, process, or service by trade name, trademark, manufacturer, or otherwise does not necessarily constitute or imply its endorsement, recommendation, or favoring by the United States Government or any agency thereof. The views and opinions of authors expressed herein do not necessarily state or reflect those of the United States Government or any agency thereof. 


\title{
Characterization and Inventories of Nuclear Materials and Wastes for Possible Future Energy Scenarios
}

\author{
Edward D. Arthur \\ Los Alamos National Laboratory
}

\begin{abstract}
Awareness of the total materials inventory and materials balance associated with differing methods for energy generation is part of present-day concerns associated with disparate areas that include atmospheric emissions, resource utilization, health effects, and both current and long-term hazards and risks. Nuclear energy, for a number of decades, has been the recipient of significant scrutiny concerning the materials and wastes it generates, particularly in the context of long-term solutions to such issues. This paper examines the nuclear materials and waste generation for nuclear energy scenarios spanning the coming century. The paper also briefly addresses wastes (in the form of emissions) from other energy sources and examines requirements associated with back-end energy system materials management. Possible future requirements pertaining to $\mathrm{CO}_{2}$ management are found to place conditions upon waste management generally similar to those for nuclear waste. One example of material flows for the case of coal generation of electricity coupled with carbon sequestration is also given.
\end{abstract}

\section{Introduction}

Nuclear energy is believed by many to be an important resource for meeting future energy needs and as an important technology for greenhouse (and other emissions) mitigation. At the same time, "back-end" fuel cycle issues associated with nuclear materials and nuclear waste production are a major area of controversy across disparate topics ranging from solutions to nuclear waste disposal to near- and long-term proliferation concerns. This paper examines the back-end materials implications from several scenarios developed for future nuclear energy use worldwide. Because the area of managing materials, emissions, and wastes from all forms of energy production has been receiving increased emphasis, the paper also briefly addresses the area of $\mathrm{CO}_{2}$ production and management. In doing so, parallels to challenges associated with nuclear waste management are drawn along with a discussion of material flows and balances associated with electricity production using coal-fired technology and subsequent carbon sequestration. 


\section{Approach}

The present paper uses results from two recent analyses of possible future nuclear energy scenarios. The first is part of a Los Alamos National Laboratory Nuclear Vision project analysis of global nuclear energy and materials scenarios. Reference 1 provides details on the models used, the analysis, and results obtained. Some pertinent information is provided here. The analysis of Krakowski, et al. ${ }^{1}$ used the ERB (Edmonds, Reilly, Barnes) global energy-economics-environment model ${ }^{2}$ to which a detailed nuclear fuel cycle description was added to replace the simplified model present in the ERB. The ERB model computes energy demand for fifteen-year time steps out to the year 2095 and then calculates market shares of a variety of energy sources (including nuclear energy). This is done for each of thirteen world regions plus a global result. The addition of a complete nuclear fuel cycle model allows calculation of a variety of nuclear materials inventories including spent fuel, plutonium, uranium resource requirements, etc. for a choice of several current and future nuclear fuel cycles. These include light-water reactors (LWRs) operating in a once-through fashion, reprocessing of LWR spent fuel to recover plutonium for use in mixed oxide fuels (MOX) in LWRs, plus advanced systems based upon reactor- or accelerator-based fast neutron spectrum burner systems. For the discussion here, most results will be provided for LWRs operating in a once-through mode since this approximates spent fuel management scenarios based on projections of current and near-term reprocessing and MOX fuel fabrication capacities.

The second analysis used results reported at the International Atomic Energy Agency Symposium on Nuclear Fuel Cycle and Reactor Strategy: Adjusting to New Realities, "Global Energy Outlook", Key Issue Paper $1^{3}$. This analysis in turn used results from other sources -- energy and nuclear energy projections from the International Energy Agency's World Energy Outlook $k^{4}$ for the period up to 2010 and International Institute for Applied Systems Analysis (IIASA) and World Energy Council projections ${ }^{5}$. The IAEA study combined multiregional results from these studies into global, developed (OECD), developing, and reforming economy (former Soviet Union countries) categories. Finally, the IAEA study used a simplified add-on nuclear materials model to determine nuclear materials and waste projections as a function of time. This model incorporated evaluations of reactor-type mixtures, fuel burnup assumptions, and capacity factor projections to create such data as well as to assess impacts of differing fuel cycle and management strategies on them.

As illustrated in Reference 1 (through a number of comparisons associated with areas such as total energy and nuclear energy demand scenarios), there appears to be reasonable consistency in projections for global and the other combined categories listed above among the references cited above. Figure 1 summarizes scenarios for nuclear energy demand over the 21st Century using results from the Los Alamos analysis of Reference 1. As indicated, they span business-as-usual, low, and high scenario variants. Again, all of these are in rough agreement with projections (out to 2050) from the IAEA study and its sources. The magnitude of upward or downward changes in nuclear energy demand 
occurs from reasonable changes in assumptions concerning population growth, implementation of tax structures for mitigation of carbon emission from fossil fuels, energy efficiency improvements, GNP growth, nuclear costs, etc. (The sensitivity of nuclear scenario projections to such assumptions are discussed more fully in Reference 1.) One final note concerns projections for nuclear energy demand beyond 2050. All three scenarios show an upturn in demand. This mirrors projections of the ERB (and other models) for total energy demand brought about by increasing world populations in developing regions and the increase in developing countries' GNP, which in turn creates demand for increased energy, even when efficiency improvements are factored in.

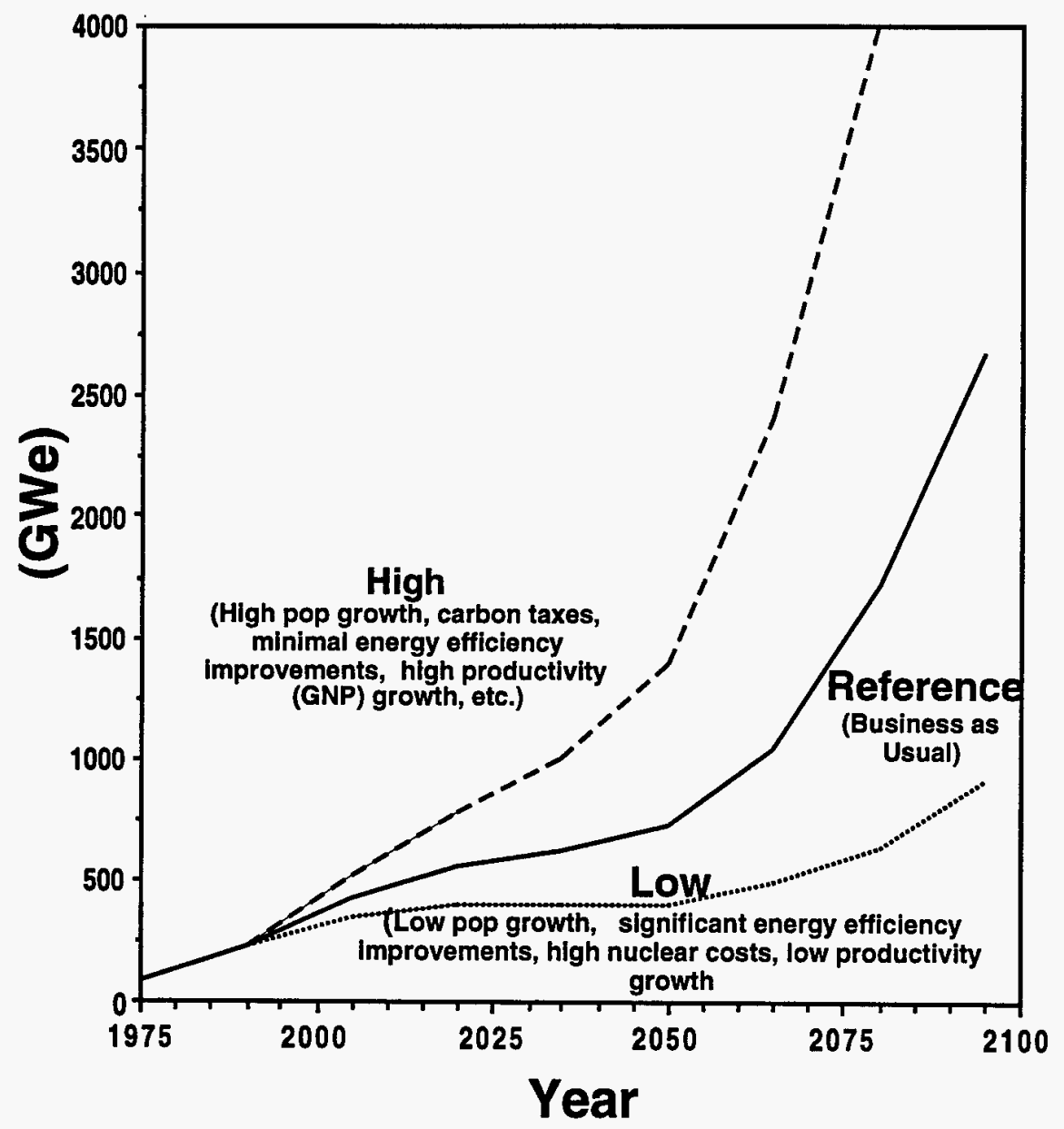

Figure 1: Global Nuclear Energy Scenarios (Reference 1)

The results from this analysis also indicate a shift in where nuclear energy could be expected to be implemented over the course of the 21 st century. Throughout the time period to 2095, nuclear energy demand in developed (OECD) and reforming economy countries is expected to stay roughly comparable to today's levels. (In this analysis, OECD country demand totals stay roughly constant because declines expected in the United States (and perhaps Europe) are offset by increases in Asian OECD members (Japan, Korea). However, developing or industrializing countries, particularly China, account for the majority of nuclear energy capacity beyond 2050 . 


\section{Nuclear Materials Projections}

Figure 2 provides scenarios for the global inventory of plutonium in spent fuel assuming no recycle and reactor fuel burnup values of $33,000 \mathrm{MWd} /$ tonne. On a global scale, such scenarios indicated plutonium growth from the current total of approximately 1000 tonnes to values between 15,000 and 40,000 tonnes by the end of the century. These figures can be changed by implementing technologies and operational practices providing increased plutonium burnup or by adopting, universally, fuel cycle strategies aimed at plutonium reuse (and potentially breeding).

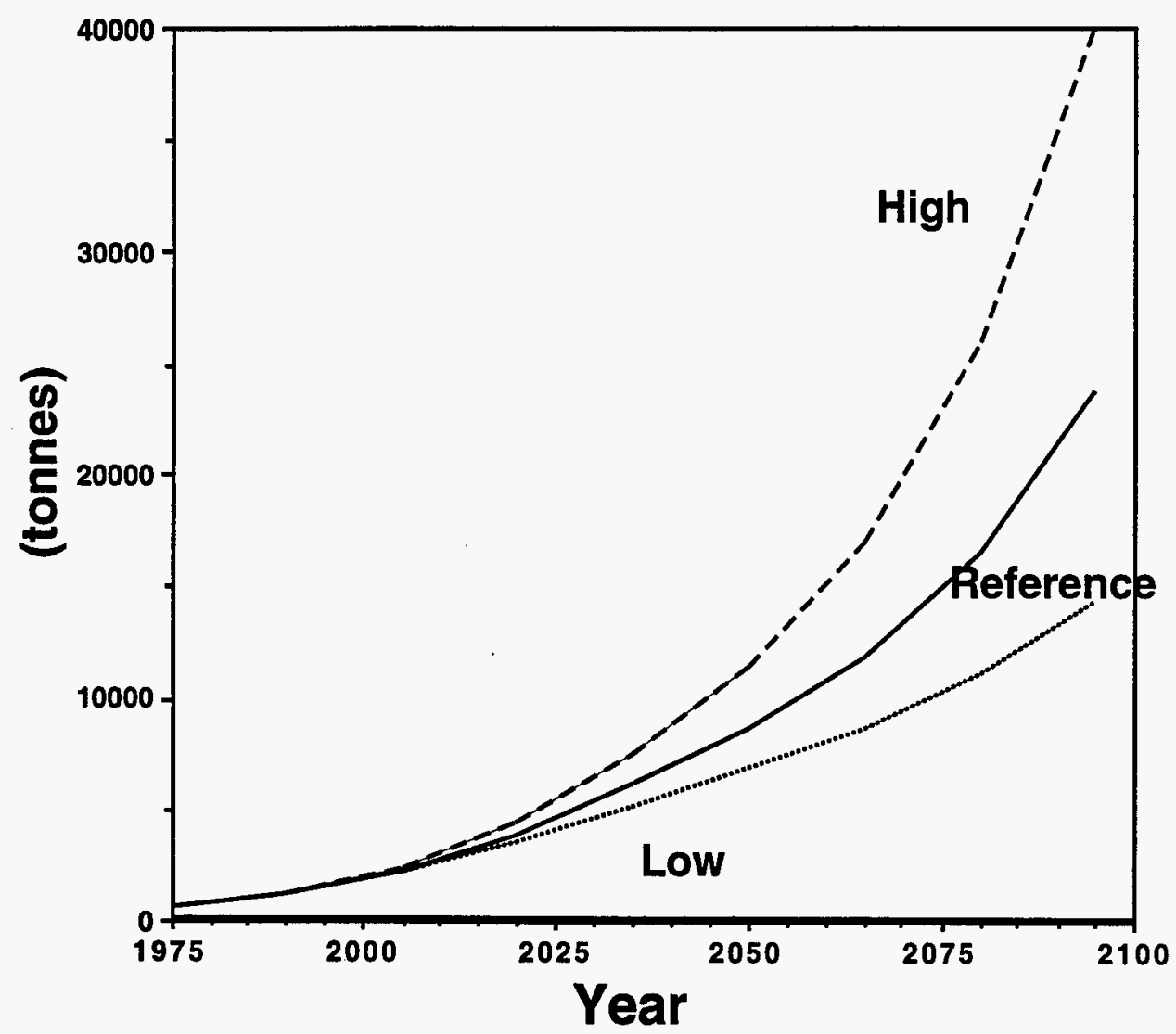

Figure 2: Global Plutonium Inventories in Spent Fuel (No Recycle Case of Reference 1)

For growth of plutonium and spent reactor fuel inventories, there is less of a shift in the location or country type versus time as compared to the nuclear demand discussed previously. This occurs because the backlog or "legacy" of spent fuel and plutonium occurring in OECD countries continues to dominate time-dependent inventory projections until almost the end of the 21 st century.

The inventory increase of spent fuel expected globally from such projections (for the "reference" case of Figures 1 and 2) is illustrated in Figure 3. Global spent fuel inventories are large (being on the order of a few hundred thousand tonnes) and grow to 
amounts ten times as great by the end of the century. However, most of this inventory is comprised of uranium which can be reused as feed to subsequent re-enrichment in LWR fresh fuel. For the example shown (determined assuming a spent fuel burnup of 33,000 $\mathrm{MWd} /$ tonne), approximately 2 to 3 percent by mass of the total amount of spent fuel is of interest (or concern) from waste management, proliferation risk, and energy recovery points of view. This situation is well known in the nuclear community but is often unappreciated or unknown outside it. Thus, material discharged from nuclear reactors can be recycled to more effectively manage it from waste and proliferation points of view. Even without use of breeder systems, a significant amount of additional energy (approaching fifty percent) could be recovered if economic or other conditions warranted it.

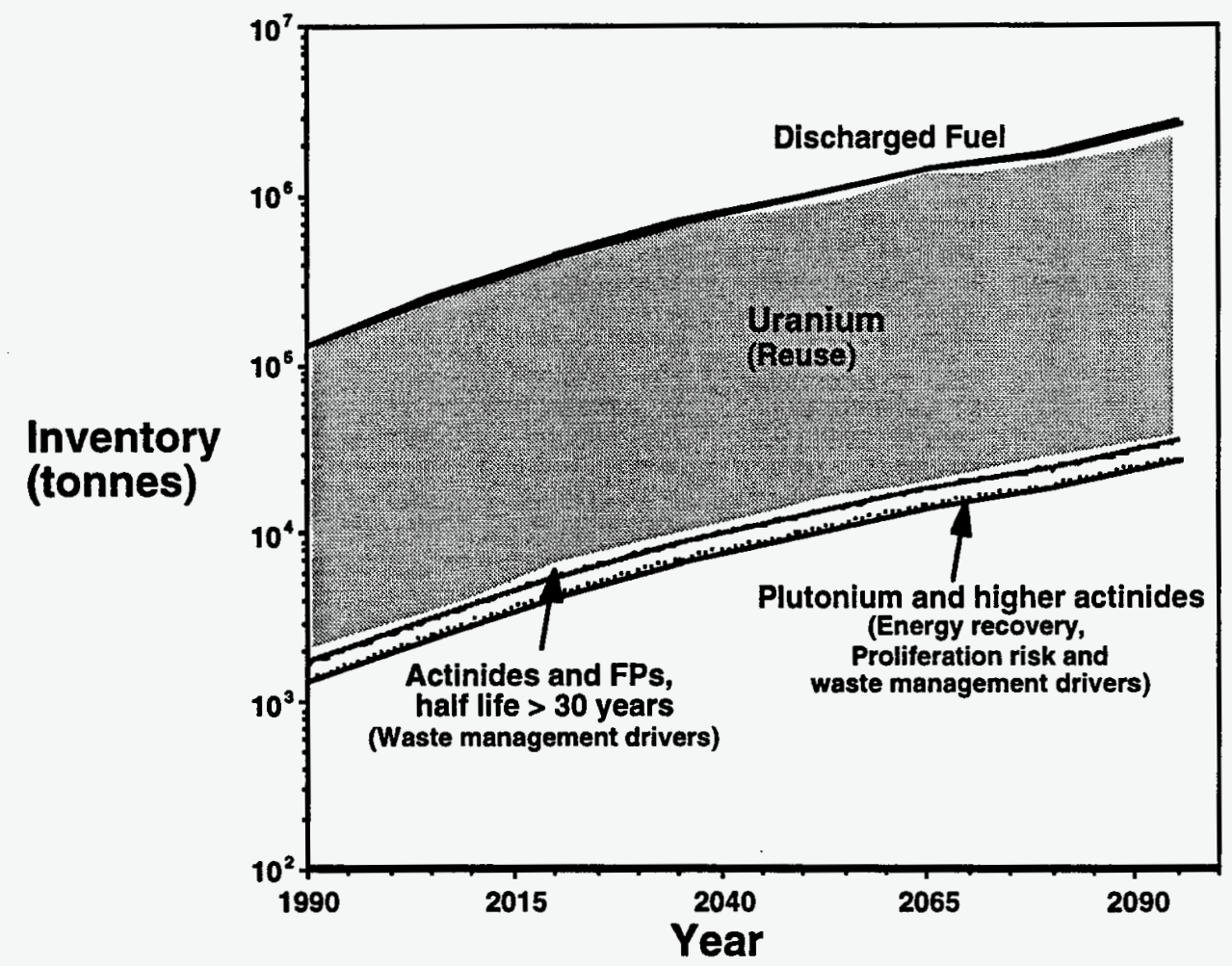

Figure 3: Discharged Fuel and Nuclear Materials Projections

The IAEA study ${ }^{3}$ also examined the fuel cycle strategy impact of recycling on the global accumulations of discharged reactor fuel. Their scenarios included fifty and one-hundred percent recycle of discharged LWR fuel via use of plutonium-containing MOX fuel in one-third LWR cores. Their projections indicated that discharged fuel inventories could be reduced by twenty-five to fifty percent over amounts expected in 2050 without recycle. Annual natural uranium requirements could also be reduced by up to twenty percent by 2050 assuming full recycle of discharged reactor fuel. 
Comparison of Material Flows and Wastes Discharged from Other Energy Sources

The issue of global climate change impacts resulting from energy production is receiving increased attention both nationally and internationally. Results ${ }^{6}$ from the ERB model indicate that the annual rate of $\mathrm{CO}_{2}$ emission could increase by close to a factor of four before the end of the next century. Cumulative $\mathrm{CO}_{2}$ emissions could double over the same timeframe. Starting around 2025, rapidly developing nations such as China could dominate $\mathrm{CO}_{2}$ production, rising to a rate close to five times greater than the United States or other currently industrialized countries by 2100 . Life cycle $\mathrm{CO}_{2}$ emissions from energy source technology are therefore receiving significant attention in addition to approaches based upon $\mathrm{CO}_{2}$ emission penalties (carbon taxes on fossil fuels), energy use and conversion efficiency improvements, and development of advanced, renewable energy sources. A number of studies have catalogued life cycle $\mathrm{CO}_{2}$ emission; Table I summarizes results from Reference 7.

Table I: $\mathrm{CO}_{2}$ Emission from Electricity Production (Reference 7) (Includes contributions from fabrication, construction, transportation, and operation).

\section{Electric Power Plant Type}

Coal

Liquid Natural Gas

Oil

Nuclear

Geothermal

Wind

Solar
$\mathrm{CO}_{2}$ Emission (g-carbon/kWhr)

237 (combined cycle) - 274

108 (fuel cell) - 180

204

$7-9$

11

9

40

If future conditions require that $\mathrm{CO}_{2}$ be sequestered, then three general approaches could be pursued -- dilution into oceans, storage using physical barriers, and combining $\mathrm{CO}_{2}$ with calcium or magnesium oxide to create mineral carbonates. $\mathrm{CO}_{2}$ storage involving physical barriers requires that such barriers be maintained indefinitely. Otherwise, the danger exists from an accidental release similar to the 1986 phenomena at Lake Nyos, Cameroon ${ }^{8}$ where a bubble on the order of $0.1 \mathrm{~km}^{3}$ (corresponding to the weekly output of a gigawatt electric power plant) was released.

A number of proposals are being developed directed towards carbon dioxide disposal in carbonate minerals. One of them ${ }^{9}$ is briefly discussed here, primarily from the point of view of material flows associated with coal-fired electricity production rather than a critique of this particular approach for $\mathrm{CO}_{2}$ sequestration. To fuel a one gigawatt (electric) power plant requires on the order of 190,000 tons per day of earth resulting in 9000 tons per day of coal to feed the plant. Approximately 24,000 tons of $\mathrm{CO}_{2}$ are 
produced daily along with other emissions (depending upon the efficiency of scrubbers and other techniques used to reduce $\mathrm{NO}_{\mathrm{x}}$ and $\mathrm{SO}_{2}$ emissions). In the proposal of Reference 10 , approximately 50,000 tons per day of rocks rich in magnesium and calcium oxide would be required for the sequestering process in addition to significant daily amounts of other materials used in the process.

This discussion indicates that present technologies for energy and electricity production often have significant materials movement, generation, and waste creation. For nuclear energy, material flows and discharged reactor fuel arisings can still be viewed as significant, but their amounts are much lower than for other energy sources. Storage of such materials also occurs in a finite number of sites (initially on-site at reactor sites followed by interim storage at a much smaller number of more centralized discharged fuel storage facilities, with plans for eventual disposal in several geologic sites in various world regions).

\section{Conclusions}

Projections from several published scenarios of nuclear energy demand trends occurring in the 21 st century have been used to determine associated inventories of discharged reactor fuel and inventories of key materials occurring in these discharged reactor stocks. Such projections indicate that "demographics" (location of nuclear power plants, type of countries where nuclear development could be expected to occur, etc.) could be significantly different over the next fifty years of nuclear power than over the past several decades. Inventories of discharged reactor fuels and plutonium in them are projected to increase by at least an order of magnitude over the next fifty to one-hundred years. This increase may serve, to some observer, as furthering the intractable nature often associated with long-term management and disposal of nuclear materials and wastes. However, current and future technological approaches based upon recycle of discharged fuel could reduce expected inventory growth by at least a factor of two (for more conventional methods of recycle) and potentially much more if advanced technologies are developed and used. Decisions on whether to do so will, however, result from a mixture of technical, political, and institutional factors that include issues associated with the overall economics of nuclear power, its acceptability, and perspectives on future proliferation dangers (real or perceived) that may be associated with civilian nuclear energy.

At the same time, the life-cycle material and waste generation from other energy sources will be subject to increasing scrutiny as more attention is paid to the coupling of energy demand, its generation, and regional and/or global environmental impacts. In particular, expected wide-spread use of coal for electricity production in developing countries will involve extremely large amounts of material flows and waste production. Additionally, efforts to mitigate emissions from the use of such fuels, particularly those aimed at dealing with $\mathrm{CO}_{2}$ control, could add significantly to such material flows. 
$\underline{\text { References }}$

${ }^{1}$ R. A. Krakowski, J. W. Davidson, C. G. Bathke, E. D. Arthur, and R. L. Wagner, Jr., "Nuclear Energy and Materials in the 21st Century", International Symposium on Nuclear Fuel Cycle and Reactor Strategy: Adjusting to New Realities, IAEA, Vienna (June 3-6, 1997).

2 J. Edmonds and J. M. Reilly, Global Energy: Assessing the Future, Oxford University Press, New York, NY (1985).

${ }^{3}$ H. F. Wagner, P. Jelinek-Fink, L. L. Bennett, and E. Bertel, "Global Energy Outlook", Key Issue Paper Number 1, International Symposium on Nuclear Fuel Cycle and Reactor Strategy: Adjusting to New Realities, IAEA, Vienna (June 3-6, 1997).

${ }^{4}$ International Energy Agency, 1996 World Energy Outlook, Organization for Economic Cooperation and Development, Paris (1996).

${ }^{5}$ N. Nakicenovic (Study Director), "Global Energy Perspective to 2050 and Beyond", World Energy Council and International Institute for Applied Systems Analysis report (1995).

${ }^{6}$ R. A. Krakowski, "The Role of Nuclear Energy in Mitigating Greenhouse Warming", Los Alamos National Laboratory Report, LA-UR-97-4891 (December 1997).

${ }^{7}$ S. Yasukawa, Y. Tadokoro, and T. Kajiyama, "Life Cycle $\mathrm{CO}_{2}$ Emission from Nuclear Power and Fuel Cycle System", Proceedings Expert Workshop on Life-Cycle Analysis of Energy Systems, Methods, and Experience, International Energy Agency, Paris (May 2122, 1992), p151.

${ }^{8}$ S. J. Freeth, "Lake Nyos: Can Another Disaster Be Avoided?", Geochemical Journal 28, 163 (1994).

9 K. S. Lachner, D. P. Butt, C. H. Wendt, "Progress on Binding $\mathrm{CO}_{2}$ in Mineral Substrates", Los Alamos National Laboratory Report, LA-UR-96-2818 (August, 1996). 
M98005647

|||||||||||||||||||||

Report Number (14) $\frac{L A-4 R-98-127}{\text { CONF-9710222- }}$

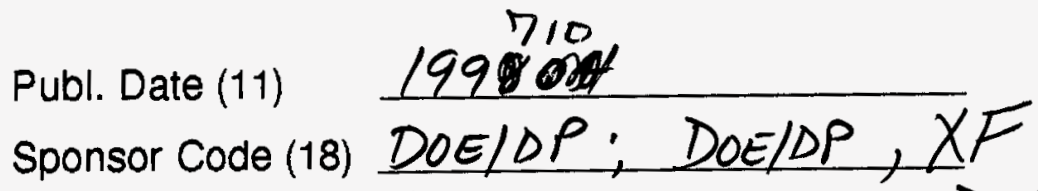

UC Category (19) UC-700; UC-721, DOE/ER

19980702039

THIC QDALITY TNQPEGTED 1

DOE 